\title{
Prescribing for people with acute rheumatic fever
}

\section{Anna P Ralph \\ Senior clinical research fellow' \\ Clinical director ${ }^{2}$ \\ Staff specialist ${ }^{3}$ \\ Sara Noonan \\ Technical adviser ${ }^{2}$ \\ Claire Boardman \\ Deputy director ${ }^{2}$ \\ Catherine Halkon \\ Projects manager ${ }^{2}$ \\ Bart J Currie \\ Professor? \\ Director $^{2}$ \\ Senior staff specialist ${ }^{3}$ \\ ' Menzies School of Health Research \\ Charles Darwin University \\ ${ }^{2}$ RHDAustralia \\ ${ }^{3}$ Department of Infectious Diseases \\ Royal Darwin Hospital \\ Darwin}

\section{Keywords}

benzathine penicillin,

rheumatic fever, rheumatic heart disease, Sydenham's chorea

Aust Prescr 2017;40:70-5 http://dx.doi.org/10.18773/ austprescr.2017.001

\section{SUMMARY}

Acute rheumatic fever and its consequence, rheumatic heart disease, remain important problems in remote indigenous Australian communities.

Aboriginal and Torres Strait Islander people living in urban settings, Maori and Pacific Islanders, and immigrants from developing countries are also likely to be at elevated risk.

Guidelines and resources are available for healthcare professionals working with at-risk populations, and for patients with acute rheumatic fever or rheumatic heart disease and their families.

There have been some recent changes in Australian recommendations for antibiotic use, dose of aspirin, first-line choice for management of severe Sydenham's chorea, and prevention of endocarditis.

For individuals diagnosed with acute rheumatic fever, the recommended treatment to prevent recurrences and development of rheumatic heart disease is benzathine penicillin $\mathrm{G}$ administered as an intramuscular injection every four weeks.

\section{Introduction}

Acute rheumatic fever is an autoimmune disease occurring in response to infection with group $A$ streptococci. Repeated or severe acute rheumatic fever episodes lead to rheumatic heart disease, a form of valvular heart disease with high morbidity and mortality.

Many healthcare providers have little experience with acute rheumatic fever and rheumatic heart disease and may be unaware of the many resources to guide diagnosis and management (see Box 1).

Much of the information available on acute rheumatic fever treatment derives from old data, ${ }^{2}$ observational studies $^{3}$ and small open-label comparative studies. ${ }^{4-6}$ It is important to be aware of the current evidence base, principles of prescribing for people with acute rheumatic fever and rheumatic heart disease, recent changes in guidelines, and available resources.

\section{High-risk populations}

Group A streptococcal infection is associated with socioeconomic factors such as household crowding ${ }^{7,8}$ Acute rheumatic fever and rheumatic heart disease are now rare in affluent societies. High rates persist among Aboriginal and Torres Strait Islander populations, especially those living in rural or remote settings. The most recent Australian Institute of Health and Welfare report highlighted rheumatic heart disease as one of the conditions accounting for the greatest rate of discrepancy between indigenous versus non-indigenous

\section{Box 1 RHDAustralia contacts and educational resources}

$\begin{array}{ll}\begin{array}{ll}\text { Control program contacts } \\ \text { Northern Territory (Top End) }\end{array} & 0889228454 \\ \text { Northern Territory (Central) } & 0889516909 \\ \text { Queensland } & 1300135854 \text { or } \\ & 0742265544 \\ \text { Western Australia } & 1300622745 \\ \text { South Australia } & 0874257146 \\ \text { New South Wales } & 1300066055 \text { or } \\ & 0293919195\end{array}$

Videos and other resources

https://www.rhdaustralia.org.au/resources

Online training modules for patients www.rhdaustralia.org.au/health-worker-modules

Online training modules for staff www.rhdaustralia.org.au/clinician-modules

Diagnosis calculator

www.rhdaustralia.org.au/apps 
Australians. ${ }^{9}$ Current estimates for definite and borderline rheumatic heart disease in Australian children range from less than 1 per 1000 population in low-risk children, to 33 per 1000 in parts of the Northern Territory. ${ }^{10}$ Maori and Pacific Islanders and immigrants from developing countries are also likely to be at elevated risk.

\section{Diagnosis}

The diagnosis of acute rheumatic fever is made using the modified Jones criteria (Table 1)." These were updated in 2015 by the American Heart Association and endorsed by the World Heart Federation to incorporate Australian recommendations for improved diagnostic sensitivity in high-risk populations.

These criteria have been built into a freely available diagnosis calculator available as a smart device application (see Box 1).12

The most challenging aspect of diagnosis is recognition, since cases can present subtly, for example as a single painful joint. There is no diagnostic test, although work towards this is an active field of research

Acute rheumatic fever is notifiable to public health units in Australian states and territories which

\section{Table 1 Australian guidelines for the diagnosis of acute rheumatic fever}

\begin{tabular}{ll} 
Diagnosis & Modified Jones criteria \\
\hline $\begin{array}{l}\text { Definite initial episode of } \\
\text { acute rheumatic fever }\end{array}$ & 2 major or 1 major and 2 minor manifestations plus evidence of a preceding group A streptococcal infection* \\
$\begin{array}{l}\text { Definite recurrent episode } \\
\text { of acute rheumatic fever in a } \\
\text { patient with known past acute } \\
\text { rheumatic fever or rheumatic }\end{array}$ & $\begin{array}{l}2 \text { major or } 1 \text { major and } 1 \text { minor or } 3 \text { minor manifestations, plus evidence of a preceding group A streptococcal infection* } \\
\text { heart disease }\end{array}$ \\
$\begin{array}{l}\text { Probable acute rheumatic } \\
\text { fever (first episode or } \\
\text { recurrence) }\end{array}$ & $\begin{array}{l}\text { A clinical presentation that falls short by either 1 major or } 1 \text { minor manifestation, or the absence of streptococcal } \\
\text { serology results, but one in which acute rheumatic fever is considered the most likely diagnosis. Such cases should be } \\
\text { further categorised according to the level of confidence with which the diagnosis is made: } \\
\text { - highly suspected acute rheumatic fever }\end{array}$ \\
\hline
\end{tabular}

\begin{tabular}{|c|c|c|}
\hline & High-risk groups $^{\dagger}$ & All other groups \\
\hline \multirow{2}{*}{ Major manifestations } & - Chorea & - Chorea \\
\hline & - Erythema marginatum & - Erythema marginatum \\
\hline \multirow{3}{*}{ Minor manifestations } & - Fever $\S$ & - Fever $\S$ \\
\hline & - $\mathrm{ESR} \geq 30 \mathrm{~mm} / \mathrm{h}$ or $\mathrm{CRP} \geq 30 \mathrm{mg} / \mathrm{L}$ & - $\mathrm{ESR} \geq 30 \mathrm{~mm} / \mathrm{h}$ or $\mathrm{CRP} \geq 30 \mathrm{mg} / \mathrm{L}$ \\
\hline & - Prolonged P-R interval on ECG\# & • Prolonged P-R interval on ECG\# \\
\hline
\end{tabular}

* Evidence includes elevated or rising antistreptolysin O or other streptococcal antibody, or a positive throat culture or rapid antigen test for group A streptococci.

+ High-risk groups are those living in communities with high rates of acute rheumatic fever (incidence >30/100 000 per year in 5-14 year olds) or rheumatic heart disease (all-age prevalence $>2 / 1000$ ). Aboriginal and Torres Strait Islander people living in rural or remote settings are known to be at high risk. Data are not available for other populations, but Aboriginal and Torres Strait Islander people living in urban settings, Maoris and Pacific Islanders, and potentially immigrants from developing countries, may also be at high risk.

$\ddagger$ A definite history of arthritis is sufficient to satisfy this manifestation. Note that if polyarthritis is present as a major manifestation, polyarthralgia or aseptic monoarthritis cannot be considered an additional minor manifestation in the same person. Chorea does not require other manifestations or evidence of preceding infection with group A streptococci, provided other causes of chorea are excluded. Care should be taken not to label other rashes, particularly non-specific viral exanthemas, as erythema marginatum.

$\S$ Fever is defined as oral, tympanic or rectal temperature $\geq 38^{\circ} \mathrm{C}$ on admission, or a reliably reported fever documented during the current illness.

\# If carditis is present as a major manifestation, a prolonged P-R interval cannot be considered an additional minor manifestation.

ESR erythrocyte sedimentation rate

CRP C-reactive protein

Source: Adapted from Table 3.2 of the Australian guideline for prevention, diagnosis and management of acute rheumatic fever and rheumatic heart disease (2nd edition) with permission from RHDAustralia 
have rheumatic heart disease control programs Western Australia, Northern Territory, Queensland, South Australia and New South Wales.13

\section{Management}

The management of acute rheumatic fever involves treatment of the infection, management of the inflammatory process and complications, and secondary prevention.

\section{Eradication of streptococcal infection}

The clinical onset of acute rheumatic fever is typically 1-4 weeks after group A streptococcal infection (longer for Sydenham's chorea).' Given this time frame, it is often not possible to isolate streptococci from cultures, but antibiotic eradication therapy is recommended nonetheless (Table 2). ${ }^{1,14-16}$ Acute rheumatic fever is well documented to occur following group A streptococcal pharyngitis (throat infection). ${ }^{17}$ In Australian indigenous communities, there is much circumstantial evidence that high rates of acute rheumatic fever can also occur after skin infection with group A streptococci. 18,19 A recent case report from New Zealand implicates antecedent skin streptococcal infection or non-group A streptococci in acute rheumatic fever. ${ }^{20}$

In most instances, penicillin can be used to clear group A streptococcal infection. It should be given as a single intramuscular dose of benzathine penicillin $G$ (also known as benzylpenicillin). The injection forms the first of the 21- or 28-day dosing schedule required for continuing secondary prophylaxis.

It is estimated that only $10-20 \%$ of patients reporting penicillin allergy are truly allergic when assessed by skin testing..$^{21}$ However, in rare instances of true allergy, azithromycin is now recommended by Therapeutic Guidelines: Antibiotic, ${ }^{14}$ Therapeutic Guidelines: Rheumatology ${ }^{15}$ and US guidelines ${ }^{22}$ for clearance of the antecedent streptococcal infection due to drawbacks with other macrolides. For example, roxithromycin appears poorly effective in achieving group A streptococci microbiological cure, ${ }^{23}$ and erythromycin is poorly tolerated.

Group A streptococci are consistently penicillinsusceptible, probably due to a lack of capacity to express beta-lactamase or to develop low-affinity penicillin-binding proteins under antibiotic pressure..$^{24}$ However, macrolide resistance was present in 3.4\% of invasive group A streptococcus isolates in Darwin in $2005-2009,,^{25}$ and in at least $30 \%$ of isolates in international studies. ${ }^{26,27}$ This is a further reason to ensure that penicillin is the treatment used whenever possible. It is important to note that penicillin or other antibiotic therapy does not influence the course or outcome of the acute rheumatic fever episode itself.

\section{Symptomatic management of joint symptoms}

Once a diagnosis of acute rheumatic fever is made, aspirin is commenced for symptomatic management. Non-steroidal anti-inflammatory drugs (NSAIDs) also appear effective. However, a major Jones criterion is migratory arthritis. If this is masked, the opportunity to make a definite diagnosis can be missed. Since joint symptoms of acute rheumatic fever often respond promptly to salicylates or NSAIDs, these should be withheld pending diagnostic certainty, with other analgesics used in the interim (Table 2).

\section{Aspirin}

Previously the recommended dose of aspirin was 80-100 mg/kg/day in divided doses. However, due to toxicity (gastrointestinal, tinnitus), the revised starting dose is $50-60 \mathrm{mg} / \mathrm{kg} /$ day although up-titration may be needed (Table 2). ${ }^{1,15}$ This is then tapered as symptoms improve and continued for 1-2 weeks after they resolve. Rebound of symptoms can occur with a rapid taper or early cessation, hence acute rheumatic fever symptoms within approximately three months of an initial episode are counted as the same episode rather than a recurrence. ${ }^{28}$

\section{NSAIDS}

The effectiveness of naproxen has been reported in a retrospective chart review of 19 patients, ${ }^{4}$ and in an open-label comparative study of naproxen and aspirin in 33 children. ${ }^{3}$ In the open-label trial, efficacy was similar to aspirin, but gastrointestinal adverse effects were fewer with naproxen. Hence although published data are scanty, NSAIDs are endorsed as an alternative to aspirin.'

\section{Symptomatic management of chorea}

Sydenham's chorea is usually self-limiting and treatment is only considered in severe cases. Carbamazepine and sodium valproate appear to have similar efficacy, ${ }^{5,6}$ with carbamazepine being recommended as first line due to a better safety profile. ${ }^{1}$ This replaces older recommendations to use haloperidol. ${ }^{5} \mathrm{~A}$ recent case report from South America describes successful use of leviteracitam for Sydenham's chorea. ${ }^{29}$ This may warrant further investigation.

\section{Management of cardiac failure}

Acute rheumatic fever with severe carditis may require pharmacological management of cardiac failure, in addition to bed rest and fluid restriction. Drugs typically include furosemide (frusemide), spironolactone, enalapril and digoxin. 


\section{Table 2 Drugs used in acute rheumatic fever}

\section{DURING ACUTE RHEUMATIC FEVER EPISODE}

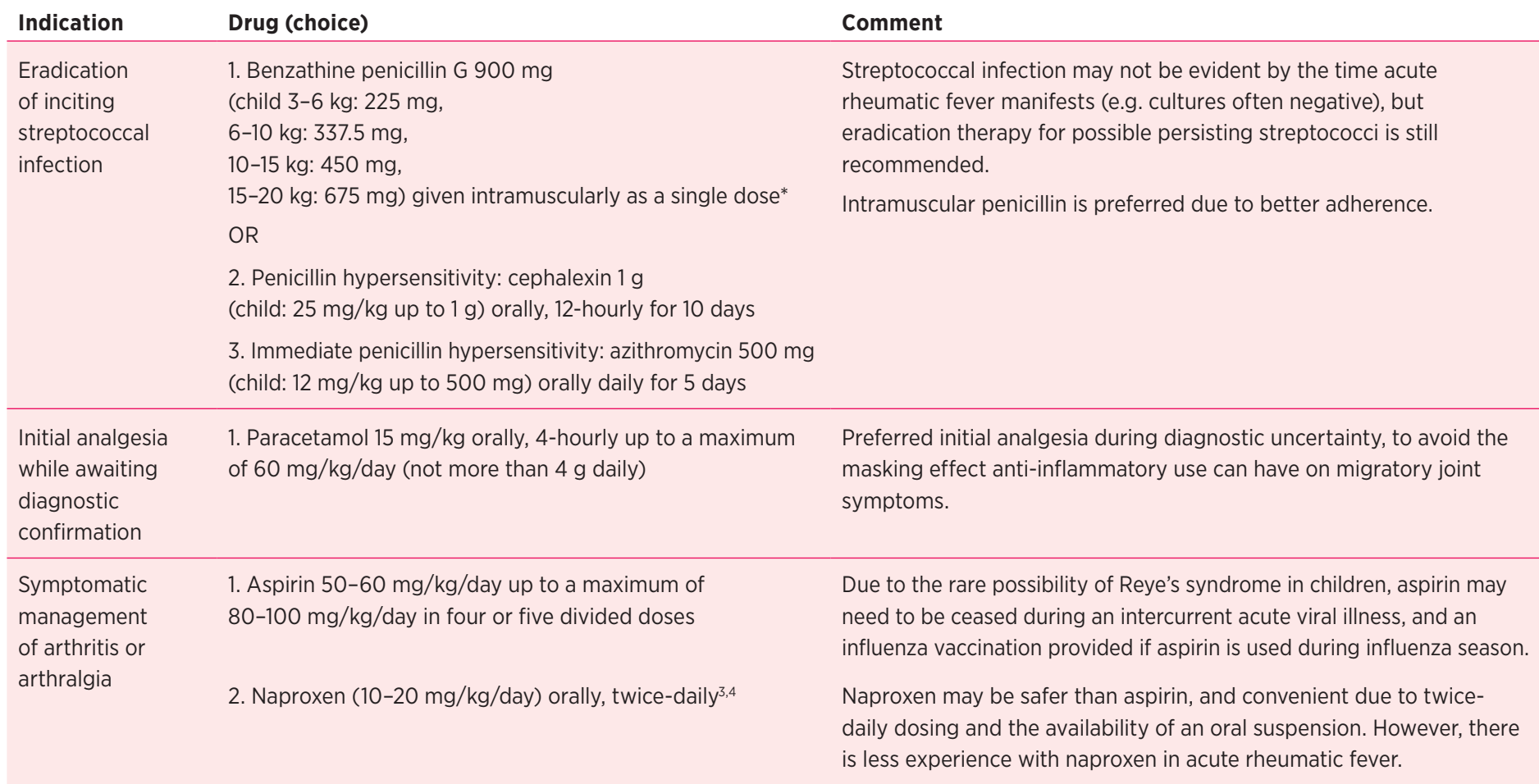

\section{SECONDARY PROPHYLAXIS}

\begin{tabular}{|c|c|}
\hline Indication & Drug \\
\hline $\begin{array}{l}\text { Prevention of } \\
\text { subsequent } \\
\text { streptococcal }\end{array}$ & $\begin{array}{l}\text { 1. Benzathine penicillin G } 900 \text { mg } \\
\text { (child <20 kg: } 450 \text { mg)* intramuscularly as a single dose } \\
\text { once every } 21 \text { or } 28 \text { days }\end{array}$ \\
\hline infections $^{16}$ & $\begin{array}{l}\text { 2. Immediate penicillin hypersensitivity: erythromycin } 250 \mathrm{mg} \\
\text { (child: } 10 \mathrm{mg} / \mathrm{kg} \text { up to } 250 \mathrm{mg} \text { ) orally } 12 \text {-hourly }\end{array}$ \\
\hline
\end{tabular}

\section{Comment}

Rare breakthrough acute rheumatic fever cases occur despite regular dosing, due to waning penicillin concentrations towards the end of the 28-day period. Therefore an injection every 3 weeks is prescribed for some individuals (generally $<2 \%$ of people with acute rheumatic fever). Oral penicillin is less effective and is not recommended except in exceptional circumstances (e.g. temporary inability to access injection while travelling)

\section{ENDOCARDITIS PROPHYLAXIS IN ESTABLISHED RHEUMATIC HEART DISEASE}

\section{Indication}

Individuals having high-risk dental or respiratory procedures

\section{Individuals} having high-risk genitourinary, gastrointestinal or infected skin or soft tissue procedures

\section{Drug}

1. Ampicillin $2 \mathrm{~g}$ (child: $50 \mathrm{mg} / \mathrm{kg}$ up to $2 \mathrm{~g}$ ) intravenously within $60 \mathrm{~min}$ (ideally $15-30 \mathrm{~min}$ ) before the procedure

2. Penicillin hypersensitivity: cefazolin $2 \mathrm{~g}$ (child: $50 \mathrm{mg} / \mathrm{kg}$ up to $2 \mathrm{~g}$ ) intravenously within $60 \mathrm{~min}$ before the procedure 3. Immediate penicillin hypersensitivity: clindamycin $600 \mathrm{mg}$ (child: $20 \mathrm{mg} / \mathrm{kg}$ ) intravenously within $60 \mathrm{~min}$ before the procedure

1. Ampicillin $2 \mathrm{~g}$ (child: $50 \mathrm{mg} / \mathrm{kg}$ up to $2 \mathrm{~g}$ ) intravenously within $60 \mathrm{~min}$ (ideally $15-30 \mathrm{~min}$ ) before the procedure

2. Penicillin hypersensitivity or immediate hypersensitivity: teicoplanin $400 \mathrm{mg}$ (child: $10 \mathrm{mg} / \mathrm{kg}$ up to $400 \mathrm{mg}$ ) intravenously within $60 \mathrm{~min}$ (ideally $15-30 \mathrm{~min}$ ) before the procedure

\section{Comment}

Note intravenous ampicillin and clindamycin can be substituted with appropriately timed oral dosing of amoxycillin or clindamycin respectively.

Note the drugs listed here which provide Gram positive cover are given in addition to any standard prophylactic recommendation required for that procedure (e.g. in combination with metronidazole plus cephazolin or gentamicin for colorectal surgery).

Note vancomycin can be used instead of teicoplanin if the timing of administration can be appropriately arranged.

* Note that the child dose of benzathine penicillin $\mathrm{G}$ is higher for secondary prophylaxis than for primary treatment.

+ High-risk procedures are defined in Therapeutic Guidelines: Antibiotic ${ }^{14}$

Source: References 1, 14 and 15 


\section{Disease-modifying treatments}

There are currently no drugs for acute rheumatic fever that effectively target the immune perturbation, or reduce the progression to, or severity of, rheumatic heart disease. Trials of corticosteroids or related compounds (adrenocorticotrophic hormone) have been unconvincing, including a comparative study of methylprednisolone and oral prednisolone in 18 patients. ${ }^{30}$ Meta-analyses have also failed to show benefit. ${ }^{31}$ Despite this, the national guideline observes that 'corticosteroids are sometimes used for severe carditis, although there is no evidence that they alter the longer-term outcome'. Internationally, steroids are used as a treatment of last resort. A randomised trial of intravenous immunoglobulin, with outcomes being time to resolution of inflammation and severity of cardiac disease, also identified no benefit in the intervention arm. ${ }^{32}$

\section{Secondary prevention}

To avoid recurrences of acute rheumatic fever and the development of rheumatic heart disease, future group A streptococcal infections need to be avoided using antibiotic prophylaxis with benzathine penicillin $\mathrm{G}$ (Table 2). Oral penicillin is strongly discouraged and is known to be associated with higher rates of acute rheumatic fever recurrence. ${ }^{16}$ This should be accompanied by advice to families about the need for prompt treatment when a suspected group A streptococcal infection occurs. They should also be advised of ways to reduce exposure at home, for example by avoiding sharing of beds when possible and culturally appropriate.

The required duration of secondary prevention for those with mild or no rheumatic heart disease is for a minimum of 10 years or until age 21 (whichever comes later), until age 35 for those with moderate heart disease, and until age 40 or longer for those with severe heart disease.

Children embarking on the daunting prospect of at least 10 years of benzathine penicillin $\mathrm{G}$ injections require sensitive, culturally appropriate engagement with healthcare systems, use of strategies to minimise the pain of injections (Box 2), and provision of tools to support adherence. Adherence resources including smartphone applications, calendars, reminder cards and incentive programs are offered at some clinics. ${ }^{33}$ Rheumatic heart disease control programs ${ }^{13}$ are a vital resource in managing people with acute rheumatic fever or rheumatic heart disease (see Box 1) by providing education and support to clinicians and patients as well as coordinating the jurisdictional registers.

Shortages or unavailability of benzathine penicillin G occur regularly in Australia and neighbouring countries with heavy burdens of acute rheumatic fever and rheumatic heart disease (e.g. Timor Leste). ${ }^{34}$ This adds a further challenge to the prevention of this serious and potentially fatal condition.

Changes in penicillin formulation over the years have required changes to the dose volumes stated in the manual provided for Aboriginal health workers and nurses working in remote areas. There have also been changes in recommendations regarding the safety of adding lignocaine to the syringe. Although adding lignocaine reduces the pain of injections, ${ }^{35}$ the manufacturer of the pre-filled syringe recommends against its use for infection control reasons.

In the setting of true penicillin allergy, the recommended alternative drug is oral erythromycin (Table 2). This is in contrast to the recommendation for azithromycin treatment of acute group $A$ streptococcal infection.

\section{Conclusion}

Healthcare providers working with people who have an elevated risk of acute rheumatic fever and rheumatic heart disease, such as in Australian indigenous communities, refugee health clinics or an area with high migrant populations, must be familiar with this important, preventable condition. Resources to aid diagnosis and management can assist clinicians working in these settings. Research is underway to generate improved knowledge and inform evidencebased guidelines. This will be incorporated in the third edition of the Australian guideline, anticipated for release in $2018 .<$

\section{Conflict of interest: none declared}

\section{Box 2 Measures that may reduce the pain of benzathine penicillin $\mathbf{G}$ injections}

Use a 21-gauge needle.

Warm syringe to room temperature immediately before use.

Allow alcohol from swab to dry before inserting needle.

Apply pressure with thumb for 10 seconds before inserting needle, or vibration before and/or during injection (e.g. see http://buzzy4shots.com.au).

Deliver injection very slowly (preferably over at least 2-3 minutes)

Distract patient during injection (e.g. with conversation)

The addition of $0.5-1 \mathrm{~mL}$ of $1 \%$ lignocaine is used elsewhere, but is not recommended with preloaded syringes currently available in Australia.

Source: Reference 
1. RHDAustralia (ARF/RHD writing groups), National Heart Foundation of Australia, Cardiac Society of Australia and New Zealand. Australian guideline for prevention, diagnosis and management of acute rheumatic fever and rheumatic heart disease. 2nd ed. Darwin: Menzies School of Health Research; 2012. https://www.rhdaustralia.org.au/arf-rhdguideline [cited 2017 Mar 1]

2. Combined rheumatic fever study group. A comparison of the effect of prednisone and acetylsalicylic acid on the incidence of residual rheumatic heart disease. Combined rheumatic fever study group. N Engl J Med 1960;262:895-902. http://dx.doi.org/10.1056/NEJM196005052621801

3. Hashkes PJ, Tauber T, Somekh E, Brik R, Barash J, Mukamel M, et al.; Pediatric Rheumatlogy Study Group of Israel. Naproxen as an alternative to aspirin for the treatment of arthritis of rheumatic fever: a randomized trial. J Pediatr 2003;143:399-401. http://dx.doi.org/10.1067/ S0022-3476(03)00388-3

4. Uziel Y, Hashkes PJ, Kassem E, Padeh S, Goldman R, Wolach B. The use of naproxen in the treatment of children with rheumatic fever. J Pediatr 2000;137:269-71. http://dx.doi.org/10.1067/mpd.2000.107158

5. Peña J, Mora E, Cardozo J, Molina O, Montiel C. Comparison of the efficacy of carbamazepine, haloperidol and valproic acid in the treatment of children with Sydenham's chorea: clinical follow-up of 18 patients. Arq Neuropsiquiatr 2002;60:374-7. http://dx.doi.org/ 10.1590/S0004-282X2002000300006

6. Genel F, Arslanoglu S, Uran N, Saylan B. Sydenham's chorea: clinical findings and comparison of the efficacies of sodium valproate and carbamazepine regimens. Brain Dev 2002:24:73-6. http://dx.doi.org/10.1016/ S0387-7604(01)00404-1

7. Jaine R, Baker M, Venugopal K. Acute rheumatic fever associated with household crowding in a developed country. Pediatr Infect Dis J 2011;30:315-9. http://dx.doi.org/10.1097/ INF.0b013e3181fbd85b

8. Wannamaker LW. The epidemiology of streptococcal infections. In: McCarty M, editor. Streptococcal infections. New York: Columbia University Press; 1954

9. Australian Institute of Health and Welfare. Australian Burden of Disease Study: impact and causes of illness and death in Aboriginal and Torres Strait Islander people 2011. Australian Burden of Disease Study series no. 6. Cat. no. BOD 7. Canberra: AlHW; 2016. www.aihw.gov.au/publicationdetail/?id=60129557110 [cited 2017 Mar 1]

10. Roberts K, Maguire G, Brown A, Atkinson D, Reményi B, Wheaton $G$, et al. Echocardiographic screening for rheumatic heart disease in high and low risk Australian children. Circulation 2014:129:1953-61. http://dx.doi.org/ 10.1161/CIRCULATIONAHA.113.003495

11. Gewitz MH, Baltimore RS, Tani LY, Sable CA, Shulman ST, Carapetis J, et al.; American Heart Association Committee on Rheumatic Fever, Endocarditis, and Kawasaki Disease of the Council on Cardiovascular Disease in the Young. Revision of the Jones criteria for the diagnosis of acute rheumatic fever in the era of Doppler echocardiography: a scientific statement from the American Heart Association. Circulation 2015;131:1806-18. http://dx.doi.org/10.1161/ CIR.0000000000000205

12. RHDAustralia. Guidelines and diagnosis calculator app. http://www.rhdaustralia.org.au/apps [cited 2017 Mar 1]

13. RHDAustralia. Rheumatic heart diseases control programs. http://www.rhdaustralia.org.au/programs [cited 2017 Mar 1]

14. Antibiotic Expert Groups. Therapeutic Guidelines: antibiotic. Version 15. Melbourne: Therapeutic Guidelines Limited; 2014.

15. Rheumatology Expert Group. Therapeutic Guidelines: rheumatology. Version 3. Melbourne: Therapeutic Guidelines Limited; 2017.

16. Manyemba J, Mayosi BM. Penicillin for secondary prevention of rheumatic fever. Cochrane Database Syst Rev 2002;3:CD002227. http://dx.doi.org/10.1002/14651858.CD002227

17. Wannamaker LW. The chain that links the heart to the throat. Circulation 1973;48:9-18. http://dx.doi.org/10.1161/01.CIR.48.1.9

18. McDonald M, Currie BJ, Carapetis JR. Acute rheumatic fever: a chink in the chain that links the heart to the throat? Lancet Infect Dis 2004:4:240-5. http://dx.doi.org/10.1016/ S1473-3099(04)00975-2
19. McDonald MI, Towers RJ, Andrews RM, Benger N, Currie BJ, Carapetis JR. Low rates of streptococcal pharyngitis and high rates of pyoderma in Australian aboriginal communities where acute rheumatic fever is hyperendemic. Clin Infect Dis 2006;43:683-9. http://dx.doi.org/10.1086/506938

20. O'Sullivan L, Moreland NJ, Webb RH, Upton A, Wilson NJ. Acute rheumatic fever following group A Streptococcus pyoderma and group G Streptococcus pharyngitis. Pediatr Infect Dis J 2017 Jan 24 [Epub ahead of print]. http://dx.doi.org/10.1097/INF.0000000000001555

21. Khasawneh FA, Slaton MA, Katzen SL, Woolbert AA Anderson SD, Parker MB, et al. The prevalence and reliability of self-reported penicillin allergy in a community hospital. Int J Gen Med 2013;6:905-9. http://dx.doi.org/10.2147/ IJGM.S54559

22. Shulman ST, Bisno AL, Clegg HW, Gerber MA, Kaplan EL, Lee $\mathrm{G}$, et al. Clinical practice guideline for the diagnosis and management of group A streptococcal pharyngitis: 2012 update by the Infectious Diseases Society of America. Clin Infect Dis 2012;55:1279-82. http://dx.doi.org/10.1093/ $\mathrm{cid} / \mathrm{cis} 847$

23. Melcher GP, Hadfield TL, Gaines JK, Winn RE. Comparative efficacy and toxicity of roxithromycin and erythromycin ethylsuccinate in the treatment of streptococcal pharyngitis in adults. J Antimicrob Chemother 1988;22:549-56. http://dx.doi.org/10.1093/jac/22.4.549

24. Horn DL, Zabriskie JB, Austrian R, Cleary PP, Ferretti JJ, Fischetti VA, et al. Why have group A streptococci remained susceptible to penicillin? Report on a symposium. Clin Infect Dis 1998;26:1341-5. http://dx.doi.org/10.1086/516375

25. Gear RJ, Carter JC, Carapetis JR, Baird R, Davis JS. Changes in the clinical and epidemiological features of group $A$ streptococcal bacteraemia in Australia's Northern Territory. Trop Med Int Health 2015;20:40-7. http://dx.doi.org/10.1111/ tmi.12405

26. Kim S, Lee NY. Epidemiology and antibiotic resistance of group A streptococci isolated from healthy schoolchildren in Korea. J Antimicrob Chemother 2004;54:447-50. http://dx.doi.org/10.1093/jac/dkh363

27. Lamagni TL, Efstratiou A, Vuopio-Varkila J, Jasir A, Schalen C, Strep E. The epidemiology of severe Streptococcus pyogenes associated disease in Europe. Euro Surveill 2005;10:179-84

28. Taranta A, Markowitz M. Rheumatic fever. 2nd ed. Massachusetts: Kluwer Academic Publishers; 1989

29. Sahin S, Cansu A. A new alternative drug with fewer adverse effects in the treatment of Sydenham chorea: levetiracetam efficacy in a child. Clin Neuropharmacol 2015;38:144-6. http://dx.doi.org/10.1097/WNF.0000000000000084

30. Câmara EJ, Braga JC, Alves-Silva LS, Câmara GF, da Silva Lopes AA. Comparison of an intravenous pulse of methylprednisolone versus oral corticosteroid in severe acute rheumatic carditis: a randomized clinical trial. Cardiol Young 2002;12:119-24. http://dx.doi.org/10.1017/ S1047951102000264

31. Cilliers A, Adler AJ, Saloojee H. Anti-inflammatory treatment for carditis in acute rheumatic fever. Cochrane Database Syst Rev 2015;5:CD003176. http://dx.doi.org/10.1002/14651858.CD003176.pub3

32. Voss LM, Wilson NJ, Neutze JM, Whitlock RM, Ameratunga RV, Cairns LM, et al. Intravenous immunoglobulin in acute rheumatic fever: a randomized controlled trial. Circulation 2001;103:401-6. http://dx.doi.org/ 10.1161/01.CIR.103.3.401

33. RHDAustralia. Resources. http://www.rhdaustralia.org.au/ resources [cited 2017 Mar 1]

34. RHD Action. Global status of BPG report: the benzathine penicillin G report. 2016. http://rhdaction.org/sites/default/ files/RHD\%20Action_Global\%20Status\%20of\%20BPG\%20 Report_Online\%20Version.pdf [cited 2017 Mar 1]

35. Amir J, Ginat S, Cohen YH, Marcus TE, Keller N, Varsano I. Lidocaine as a diluent for administration of benzathine penicillin G. Pediatr Infect Dis J 1998;17:890-3. http://dx.doi.org/10.1097/00006454-199810000-00008 